\title{
Malignant: Examining the evidence on which we base cancer care
}

\author{
DALE E HAMMERSCHMIDT
}

\begin{abstract}
Vinayak K Prasad, Malignant: How bad policy and bad evidence harm people with cancer, Johns Hopkins University Press, 2020, 289 pgs, US\$ 32.95 (Kindle Rs 1794.19) ISBN: 9781421437635
\end{abstract}

When reading the early chapters of this book, I often found myself smiling - remembering similar conversations I had had with colleagues as we faced overenthusiastic news coverage of new developments, or as we worried about what we termed the "false prophets" of evidence-based medicine (those who neglected the step of evaluating the quality and generalisability of the evidence on which they were basing recommendations). I quickly recognised, however, that $\mathrm{Dr}$ Prasad was taking our concerns in a more useful direction: he explains the issues in language that is accessible to people who are not themselves researchers or oncologists, and he organises them in a way that leads to understanding of their origins and to suggestions for improvement.

Thalidomide was a sedative drug with strong anti-nausea properties and with very little respiratory depression. It was thought to be uniquely safe, in that overdoses didn't easily kill people; it found favour in treating the nausea of early pregnancy. In the wake of the discovery that thalidomide was also an angiogenesis inhibitor and caused very serious birth defects, the United States adopted the 1962 Kefauver-Harris amendments to the Pure Food, Drug and Cosmetics Act of 1938 - requiring the manufacturers of new drugs to provide evidence of safety and efficacy before marketing approval could be granted. While this seemed a good idea at first, it placed the responsibility for generating the supporting data on those destined to profit from drug approval; a greater conflict of interest is hard to imagine. This same arrangement persists today, and frequently contributes to difficulty in developing, understanding and using cancer therapies. Conflict of interest in its many guises is a theme throughout the book; a chapter is specifically devoted to financial conflicts, but the lesser conflicts are a background ostinato.

Author: Dale E Hammerschmidt (hamme001@gmail.com), Emeritus Professor of Medicine, Division of Oncology and Transplantation, University of Minnesota Medical School, Minnesota, USA.

To cite: Hammerschmidt DE. Malignant: Examining the evidence on which we base cancer care. Indian J Med Ethics. 2021 Apr-Jun; 6(2) NS: 177-178. DOI: 10.20529/IJME.2020.127.

Published online first on December 12, 2020.

Manuscript Editor: Sanjay A Pai

(C) Indian Journal of Medical Ethics 2020
Prasad reminds us again and again that not all conflicts arise from malice; less rigorous study procedures and outcome criteria may be chosen for the sake of speed or economy.

Perhaps the greatest strength of this work is the careful examination of each of several major contributors to problems in interpreting (and depending upon) clinical research findings. The author's unusual skill in making these issues understandable to a lay audience is evident time and again. Particular attention is given to the use of surrogate endpoints and their ability to mislead, as for example when a large effect on disease-free survival fails to predict a benefit in overall survival. There is a certain tension between a fair treatment of the complex issues and a desire to keep the text accessible. Prasad confronts this with refreshing candour: he suggests that the reader skip the technical parts if they are getting in the way, and return to them later if the details prove important to the task at hand.

Another chapter I was glad to see was one devoted to the distortions in perceptions of cancers and their treatment that come from high expectation of novelty, from overly optimistic presentation of study results, and from selection of atypically good results for human-interest news stories. My own pet peeve in this realm is the selection of misleading headlines for on-line presentations, seeking the "click density" that improves ad revenue for a publisher.

Overall, the book is a laudable effort to make a mysterious world less so, providing a fine primer for people involved in developing health policy and useful enrichment for people making careers in cancer medicine. But its closing feature may, in the long run, be even more important - a discussion of avenues to pursue in an attempt to make things better. The author suggests several ways in which federal agencies could tighten procedures and expectations without having to amend statutes or regulations. As one might expect, more rigorous use of surrogate endpoints is highlighted, as is careful attention to the actual expected benefit of a novel agent in typical patients (as opposed to the ideal candidates who typically populate the clinical trials leading to licensure).

Discussions of what cancer patients can do and what cancer physicians can do are short, and made me hope for a sequel in which the issues will be addressed more thoroughly. The importance of a truly informed dialogue is stressed, with a bit of a lament about how difficult that can be in a setting of medical care that is centered about cash flow and throughput. Political activism toward improving policy is stressed, as is involvement with advocacy groups.

The book ends with some ruminations about what would be features of a successful cancer policy. Three headings from that chapter: "Evidence - Measure What Matters, and Do It 
Fairly";"Relevance - Our Studies Must Aid Average People with Cancer"; "Affordability - Successful Therapies must be Broadly Available." Obviously, Prasad has chosen these goals as we currently fail to achieve them.

Although I've put it near the end of my discussion, Prasad opened with a story that was close to my heart and involved several close friends. Bone marrow suppression was often the dose-limiting toxicity in the treatment of breast cancer with regimens centred around alkylating agents, anthracyclines and taxanes. Yet it appeared that dose increments were still improving outcomes, even at the high end. It seemed reasonable that stem-cell autografts (preserving some marrow in storage, and giving it back after the marrow-toxic treatment had been given) would allow more intensive therapy and achieve greater benefit. After a pilot experience, enthusiasm was great, and the therapy became standard at some centres; at least one state in the US passed a law guaranteeing access.
But when a rigorous multicenter prospective controlled trial was finally carried out, the benefit was nowhere to be found. A good friend was the site principal Investigator at one participating centre; her simple summary (paraphrased): "I think we killed about the same number that we cured." Prasad's book asks: What went wrong, here? What can we learn from stories like this one? How can we do it better next time? He nudges us toward answers.

Although Prasad is himself a haematologist/oncologist and builds this narrative around cancer and cancer therapy, many of the conclusions are generalisable. This is a good read for anyone interested in medical evidence.

As befits the intended audience - a mixture of people in the field and people very much not in the field - the author provides a helpful bibliography. The work has extensive citations.

\title{
Are you being managed?
}

\author{
JON JUREIDINI
}

\section{Sergio Sismondo, Ghost-managed medicine: Big Pharma'sinvisible hands, Manchester, UK: Mattering Press; 2018. Pgs 152. ISBN: 978-0-9955277-7-5 (paperback), ISBN: 978-0-9955277-8-2 (e-book). $£ 16$ (paperback).}

(Open access; download available from: https:// www.matteringpress.org/wp-content/uploads/2018/07/

Sismondo-Ghost-managed-Medicine-2018-1.pdf)

There are at least 15 points of intervention by the pharmaceutical industry in the causal pathway from a TV ad to a prescription. Ghost-managed medicine exposes Big Pharma's calculated control of this pathway. Many of the interventions might appear to come from outside industry with contributions from seemingly independent researchers, medical experts, regulators and consumer organisations. But it is all carefully and ruthlessly orchestrated by industry; egregious examples from the United States include the

Author: Jonathan Jureidini (jon.jureidini@adelaide.edu.au), Research Leader and Child Psychiatrist, Robinson Research Institute, Adelaide University, Adelaide, South Australia, AUSTRALIA.

To cite: Jureidini J. Are you being managed? Indian J Med Ethics. $2021 \mathrm{Apr}-$ Jun; 6(2) NS: 178-179. DOI: 10.20529/IJME.2020.094.

Published online first on September 8, 2020.

Manuscript Editor: Sanjay A Pai

(C) Indian Journal of Medical Ethics 2020
Orwellian "patient advocacy" group, Centre for Medicine in the Public Interest, created as a voice for Big Pharma and controlled by it.

Sismondo's methodology was to attend what he describes as "penumbral" conferences that addressed, inter alia, marketing, management of key "opinion leaders" and publication planning. Here the tactics of industry are discussed with a frankness that is lacking in more academic forums. Sismondo and his collaborators collected rich data with many shocking narratives.

From time to time, Sismondo reminds us that industry science is not necessarily bad science; that input from the marketing division might not necessarily be corrupt because there is a correlation between a drug being marketable and being good. For example, he writes of publication planners: "they appeared to be trying to be honest and to be striving for sound science, while serving the interests of drug companies' marketing departments" (pp 89-90). The implication is that a system driven by profit rather than ethics might still be good for our health.

Sismondo's book covers some of the same ground as one I have recently published with philosopher Leemon McHenry (The illusion of Evidence-Based Medicine, Wakefield Press, 2020). We agree on most things but disagree with his implication that industry science might generally have good outcomes. We think the capitalist model of essentially unregulated science does unacceptable harm. Sismondo provides little 